\title{
Anesthesiological Management of Eclampsia in Tropical Africa: Experience of the University Hospital Center of Bouake
}

\section{Kouadio Konan Stéphanie1, Irié Bi Gohi Serge 1*, Pete Yaich1, Koffi N’Guessan', Yao Konan Christian², Ogondon Bernard', Nda-Koffi Cinthia', Samake Yaya ${ }^{3}$, Kouame Konan Edmond', Brouh Yapo'}

\author{
${ }^{1}$ Anesthesia-Intensive Care Unit, Bouake Hospital, Bouake, Ivory Coast \\ ${ }^{2}$ Pediatric Department, Bouake Teaching Hospital, Bouake, Ivory Coast \\ ${ }^{3}$ Obstetrics and Gynecology Department, Bouake Teaching Hospital, Bouake, Ivory Coast \\ Email: *iriebi_gohiserge@yahoo.fr
}

How to cite this paper: Stéphanie, K.K., Serge, I.B.G., Yaich, P., N'Guessan, K., Christian, Y.K., Bernard, O., Cinthia, N.-K., Yaya, S., Edmond, K.K. and Yapo, B. (2018) Anesthesiological Management of Eclampsia in Tropical Africa: Experience of the University Hospital Center of Bouake. Open Journal of Anesthesiology, 8, 93-99. https://doi.org/10.4236/ojanes.2018.83010

Received: March 2, 2018

Accepted: March 18, 2018

Published: March 21, 2018

Copyright $\odot 2018$ by authors and Scientific Research Publishing Inc. This work is licensed under the Creative Commons Attribution International License (CC BY 4.0).

http://creativecommons.org/licenses/by/4.0/

\section{(c) (i) Open Access}

\begin{abstract}
Introduction: Eclampsia is a common cause of maternal mortality in developing countries. The objective of this study is to evaluate the practice of anesthesia for eclampsia in tropical Africa. Patients and Methods: Retrospective descriptive study on the parturients who benefited from eclampsia anesthesia in the operating theaters of the gynecology and obstetrics department, the University Hospital Center (CHU) of Bouake over a two-year period (January 2015 to December 2016). The parameters studied were: anesthetic risk assessment, anesthetic management, immediate anesthetic and post-anesthetic accidents and incidents. Results: Out of a total of 3831 emergency cesarean sections, 65 were for eclampsia, or $1.69 \%$ of obstetrical surgical activity. The mean age of the patients was $20.30 \pm 3.34$ years (range: 14 years and 39 years). Prenatal consultation was not performed in $70 \%$ of cases and $85 \%$ of patients were primiparous. Patients classified as $\mathrm{ASA} \mathrm{III}_{U}$ accounted for $75 \%$ of the population and in $62 \%$ of cases, the Glasgow score was between 9 and 12. Induction was achieved with thiopental in $98 \%$ of patients and vecuronium was the only muscle relaxant used. The most common fetal complications were hypotrophy (50\%), prematurity (30\%) and respiratory distress (40\%). Postoperative anesthetic complications were agitation (70\%) and wake delay (15\%). Maternal mortality was $5 \%$ and the neonatal death rate was around $7.69 \%$. The elements of poor maternal prognosis were the ASA IV $\mathrm{IV}_{\mathrm{U}}$ class $(\mathrm{P}=$ $0.015)$ and the Aldrete awakening score between 3 and 5 awakening $(P=$ 0.001). Conclusion: Anesthesia for eclampsia at $\mathrm{CHU}$ of Bouake is difficult. It needs to be improved thanks to better equipment of the health structures.
\end{abstract}




\section{Keywords}

Eclampsia, Emergency, Anesthesiology, Ivory Coast

\section{Introduction}

Eclampsia is a paroxysmal and formidable neurological complication of toxemia of pregnancy [1]. It is a very rare condition in developed countries with a prevalence of $0.49 \%$ [2], but it remains constant in developing countries, where its prevalence varies between $0.58 \%$ and $6.15 \%$ [3]. It is one of the leading causes of maternal mortality in developing countries [4] with over 50,000 deaths per year [1] [5]. The treatment of eclampsia is medico-obstetrical. It is based on urgent and immediate evacuation of the uterine cavity regardless of the term or the maternal-fetal resuscitation. This evacuation of the fetus from the maternal genital tract requires the completion of an emergency cesarean section performed under anesthesia. Anesthesia under these emergency conditions is a high-risk anesthesia for the mother-child couple [1]. In Bouake, the second-largest city in Ivory Coast, data on anesthesia for eclampsia are non-existent. The objective of this work is to evaluate the practice of anesthesia for eclampsia at the University Hospital Center of Bouake.

\section{Patients and Methods}

This was a descriptive and retrospective study carried out over a 2-year period (January 2015 to December 2016) in the operating theaters of the obstetrics and gynecology department of the Bouake University Hospital. All patients with severe pre-eclampsia complicated by one or more general convulsions were defined as eclamptic. All patients admitted for eclampsia who benefited from a maternal lifesaving caesarean section under anesthesia were included in our study. Eclamptic patients who were not operated on or had incomplete records and were not included in our study. The data was collected from a pre-established survey form and the methodology consisted in filling them out from the selected files. The parameters studied were: anesthetic risk assessment, anesthetic management, anesthesiologist's degree, immediate anesthesia and post-anesthetic accidents and incidents. We used the American Society of Anesthesiology (ASA) classification to perform anesthetic risk assessment. The risks of difficult mask ventilation were assessed by: body mass index $(\mathrm{BMI})>26$, age $>$ 55 years, toothlessness, snoring and the difficulty of mandibular protusion. The risks of difficult intubation were assessed by: the Mallampati score, the presence of prominent incisors, the stiffness of the neck, the opening of the mouth, the thyro-chin distance. The data was exploited using the Epi info software version 3.5.3. The comparison of the qualitative variables was made with the statistical tests with a value of $P$ less than 0.05 retained as threshold of significance of the differences observed. 


\section{Results}

\subsection{Demographic Parameters}

During this period, out of a total of 3831 cesareans performed for obstetric emergencies, 65 of them were for eclampsia or $1.69 \%$ of the surgical obstetric activity of the CHU Bouake. Patients aged between 15 and 19 years were mostly represented ( $73 \%$ of cases) (Table 1 ). The mean age of the patients was $20.30 \pm$ 3.34 years (range 14 years and 39 years). Out-of-school patients were in the majority with $84 \%$ of cases. Primiparous women accounted for $85 \%$ of the strength of our series. The average gestational age was $35 \pm 2$ weeks of amenorrhea (range: 34 weeks and 38 weeks of amenorrhea), and the vast majority of patients in our series $(70 \%)$ did not have an antenatal visit. the number of patients who were admitted with a Glasgow score between 9 and 12 made up 62\% of our series (Table 1). Magnesium sulfate and injectable nicardipine were administered to all patients. Active acute renal failure (15\%) and HELLP Syndrome (10\%) were the main complications associated with eclampsia. The pre-anesthetic evaluation of the patients was carried out by anesthesia physicians and the anesthetic inductions were performed by nurse anesthetists. Patients classified ASA $\mathrm{III}_{U}$ and $\mathrm{ASA} \mathrm{IV}_{\mathrm{U}}$ accounted for $75 \%$ and $25 \%$ of our workforce, respectively.

\subsection{Conduct of Anesthesia}

The time to surgical management was less than 1 hour in all patients. General anesthesia was the only anesthetic technique used and in all cases it was performed by a nurse anesthetist. The products used for intravenous induction were thiopental (98\%) and propofol (2\%). Tracheal intubation was performed in all patients and vecuronium was the muscle relaxant administered in all cases. Fentanyl was the only analgesic used after clamping the cord. Maintenance of general anesthesia was provided by halothane in all cases. The maximum time to

Table 1. Patient distribution according to clinical characteristics $(n=65)$.

\begin{tabular}{ccc}
\hline Parameters & Number & Percentage \\
\hline$<15$ & Age (years) & 3 \\
$15-19$ & 2 & 73 \\
$20-24$ & 48 & 9 \\
$25-29$ & 6 & 9 \\
$>30$ & 6 & 6 \\
\hline $15-13$ & 4 & 18 \\
$12-9$ & Glasgow score & 62 \\
$8-6$ & 12 & 14 \\
$<6$ & 40 & 6 \\
\hline
\end{tabular}


fetal extraction was 5 minutes after incision, followed by 10 units of syntocinon and amoxicillin. The most common fetal complications during the study were respiratory distress (40\%), prematurity (32\%) and hypotrophy (25\%).

\subsection{Unwanted Events}

Tachycardia was the most observed intraoperative complication (40\%) (Table 2). The postoperative awakening was evaluated thanks to the aldrete score which was between 3 and 5 in 12\% of cases (Table 3). Postoperative complications were dominated by agitation ( $60 \%$ of cases) and delay in waking ( $15 \%$ of cases). Postoperative management of patients included: administration of magnesium sulfate $(100 \%)$, nicardipine (70\%) and thrombophylaxis (60\%). In our series, $12.3 \%$ of patients received ventilatory support. In $15 \%$ the administration of furosemide preceded by a filling was necessary for the management of acute renal failure. None of our patients benefited from extra-renal cleansing. The duration of hospitalization was between 0 and 5 days in $90 \%$ of cases with an average duration of 3 days. Maternal mortality was $5 \%$ and the neonatal death rate was around $7.69 \%$. The elements of poor maternal prognosis were the ASA IVU class $(\mathrm{P}=0.015)$ and the Aldrete awakening score between 3 and $5(\mathrm{P}=0.001)($ Table $4)$.

\section{Discussion}

\section{Limitations of the Study}

This study makes it possible to describe, for the first time, anesthesia for eclampsia at the hospital and university center of Bouake. It allows us to highlight all the difficulties that limit this practice in our context. This study of many bias linked as a part to the nature retrospective of the study and other part to all patients with eclampsia in the Bouake area were not treated at the university hospital Center of Bouake. However, it offers us many points of discussion.

Table 2. Distribution of patients according to intraoperative complications $(n=30)$.

\begin{tabular}{ccc}
\hline Intraoperative complications & Number & Percentage \\
\hline Tachycardia & 12 & 40 \\
Bradycardia & 02 & 07 \\
Voltage thrust & 12 & 40 \\
Hypotension & 04 & 13 \\
Total & 30 & 100 \\
\hline
\end{tabular}

Table 3. Distribution of patients by aldrete awakening score $(n=65)$.

\begin{tabular}{ccc}
\hline Aldrete Score & Number & Percentage \\
\hline $3-5$ & 08 & 12 \\
$6-8$ & 34 & 53 \\
$9-10$ & 23 & 35 \\
Total & 65 & 100 \\
\hline
\end{tabular}


Table 4. Distribution of patients by prognostic factors $(n=65)$.

\begin{tabular}{|c|c|c|c|}
\hline \multirow{2}{*}{ Parameter } & \multicolumn{2}{|c|}{ Evolution } & \multirow{2}{*}{$\mathrm{P}$} \\
\hline & Favorable & Death & \\
\hline \multicolumn{4}{|c|}{ ASA Class } \\
\hline 3 & 49 & 0 & \multirow{2}{*}{0.01} \\
\hline 4 & 13 & 3 & \\
\hline \multicolumn{4}{|c|}{ Aldrete score } \\
\hline $3-5$ & 5 & 3 & \multirow{2}{*}{0.001} \\
\hline$>5$ & 57 & 0 & \\
\hline \multicolumn{4}{|c|}{ Narcotic } \\
\hline Pentothal & 61 & 3 & \multirow{2}{*}{0.95} \\
\hline Propofol & 1 & 0 & \\
\hline
\end{tabular}

During the study period, 1260 emergency cesareans were performed with 65 eclampsia cases; an incidence of $5.15 \%$. The age group most affected during the study was $15-20$ years, i.e. $76 \%$ of the population for an average of $20.30 \pm 3.34$ years and extremes of 14 and 39 years. In the series, primiparous women accounted for $85 \%$ of cases. Young age and primiparity are predisposing factors, as highlighted by several studies [6] [7] [8] [9]. A large majority of patients in our series $(70 \%)$ did not have an antenatal clinic. This lack of follow-up of pregnancies would explain the occurrence of eclampsia in our patients. Out-of-school patients were the majority in the study population with $84 \%$ of cases. This low rate of education would explain the low rate of antenatal care. The ASA $\mathrm{III}_{\mathrm{U}}$ class was mostly represented in the series with $75 \%$ of cases. However, the ASA class 4 was $25 \%$; this could be explained by a delay in the care. General anesthesia was the preferred technique in all patients preceded by pre oxygenation mask. Thiopental, the narcotic of choice in fast-sequence anesthesia, was widely used, accounting for $98 \%$ of cases. The administration of succinylcholine, which should be systematic because of the risk of inhalation and difficult intubation, was not possible because of its unavailability during the study period. Vecuronium was the only muscle relaxant used. Orotracheal intubation was performed in all our patients as proposed in several studies Arvieux et al. [10], JL Pourriat et al. [11]. We did not encounter any cases of intubation due to difficult intubation. Our findings were superimposable with those of Simazoe et al. [12] who recorded no cases of intubation failure in their series. The maximum extraction time was 4 minutes after incision, followed by the administration of 10 units of syntocinon and amoxicillin. The most frequent fetal complications during the study were hypotrophy $50 \%$ of cases, prematurity $30 \%$ of cases and acute respiratory distress in $40 \%$ of cases. The neonatal death rate was $7.69 \%$. This rate was significant but less important than that of Simazoe et al. [12] who reported $20 \%$ fetal mortality. This could be explained by an improvement in the quality of the management of patients. The post-operative awakening was evaluated thanks to the aldrete score which was 3 to 5 in $12 \%$ of cases. This period was marked by 
complications namely: Agitation (60\% of cases) that could be due to pain and delayed wake up (15\% of cases) that could be explained by an overdose of anesthetic drugs. The administration of magnesium sulfate was systematic in all patients for the prevention and treatment of seizures. In fact, magnesium sulphate has shown superiority over benzodiazepines, as several studies have shown [13] [14]. However, seizures in the ward have been treated with diazepam. The management of arterial hypertension was provided by nicardipine. Since postoperative pain after Caesarean section was a moderate pain during the first 48 hours, her management consisted of balanced analgesia combining morphine with other level 1 or 2 analgesics. Thromboprophylaxis was performed in $60 \%$ of our patients. In the study series, $12.3 \%$ of patients received ventilatory support. This rate is lower than that of Brouh et al. [6] who reported 23\%. In the series, $14.7 \%$ of patients had functional renal impairment that was supported by the use of furosemide prior to filling. None of our patients benefited from extra-renal dialysis treatment. The duration of hospitalization was 0 to 5 days in $90 \%$ of cases with an average of 2 days. During the study, maternal mortality was 5\%. This rate was lower than that of Simazoe et al. [12] who reported a maternal mortality of $26.6 \%$. This could be explained by the speed with which patients are treated.

\section{Conclusion}

Despite the anesthesiological prowess of recent years, the anesthesia of eclamptic patients in Bouake remains difficult. It is a delicate anesthesia performed urgently in health facilities with a limited technical platform. The anesthetic technique remains the general anesthesia. An improvement in the technical platform would make it possible to avoid maternal-fetal mortality factors and would contribute to improving the survival rate of the eclamptic patients.

\section{Conflicts of Interest}

The authors do not declare any conflict of interest.

\section{References}

[1] Diouf, A.A., Diallo, M., Mbaye, M., Sarr, S.D., Faye-Dieme, M.E., et al. (2013) Epidemiological Profile and Management of Eclampsia in Senegal: About 62 Cases. Pan African Medical Journal, 16, 1-5.

[2] Robson, S.C. (1999) Hypertension and Renal Disease in Pregnancy. In: Edmonds, D.K., Ed., Dewhurst's Textbook of Obstetrics and Gynaecology for Postgraduates, 6th Edition, Blackwell Science Ltd., London, 166-185.

[3] Pambou, O., Ekoundzola, J.R., Malannoat, J.P. and Buambo, S. (1999) Prise en charge et pronostic de l'éclampsie au CHU de Brazzaville. A propos d'une étude rétrospective de 100 cas. Medecine d' Afrique Noire, 46, 508-512.

[4] Samake, B.M., Traore, M., Goita, L., Niani, M., Traore, Y., et al. (2011) Epidemiogic and Clinical Profile of Severe Pre-Eclampsia at the Teaching Hospital of Gabriel Touré. Mali Medical, 26, 5-7.

[5] Rakotomahenina, H., Rajaonarison, T.J., Randriamahavonjy, R. and Andrianampanalinarivo, R. (2009) Why Does Eclampsia Cause High Mortality? A Study in the 
Maternity of Befelatanana. Revue dAnesthésie-Réanimation et de Médecine d Urgence, 1, 25-27.

[6] Brouh, Y., Gimel, P., Denis, Y. and Akpo, A. (2008) Eclampsies in a University Hospital in Côte d'Ivoire: Management, Evolution and Prognostic Factors. Canadian Journal of Anesthesia, 55, 423-428.

[7] Nirina, H., Rasolonjatovo, T.Y., Andrianirina M., Randriambololona, D.M.A., Andrianjatovo, J.J. and Randriamiarana, J.M. (2009) Epidemiological Profile of Pre-Eclampsia and Eclampsia Admitted to the Adult Resuscitation of Befelatanana Maternity Hospital (Madagascar). Revue d Anesthésie-Réanimation et de Médecine dUrgence, 1, 22-24.

[8] Aya, A.G.M., Vialles, N. and Ripar, J. (2010) Anesthesia and Pre-Eclampsia. Annales Françaises d Anesthésie et de Réanimation, 29, e141-e147.

https://doi.org/10.1016/j.annfar.2010.03.014

[9] Ducarme, G., Herrnberger, S., Pharisee, I., Carbillon, L. and Uzan, M. (2009) Eclampsie, Retrospective Study of 16 Cases. Gynecologie, Obstetrique \& Fertilite, 37, 11-17. https://doi.org/10.1016/j.gyobfe.2008.11.011

[10] Arvieux, C.C., Rossignol, B., Guéret, G. and Havaux, M. (2001) Anesthesia for Emergency Cesarean Section. In: SFAR, News Conference, $43 \mathrm{rd}$ National Congress of Anesthesia and Resuscitation, Elsevier, Paris, 9-25.

[11] Pourriat, J.L., Carli, P., Hamza, J., Journois, D., Mignon, A., Safran, D., Ozier, Y., Samama, M., Haberer, J.P. and Orliaguet, G. (2007) Anesthesia and Sedation in Emergency Situations. 2nd Edition, Arnette, Paris, 147-156.

[12] Simazue, A., Benamar, B., Ngaka, D. and Nguemby Mbina, C. (1996) Management of the Eclamptic Patients at the Hospital Center of Libreville. Revue d Anesthésie-Réanimation et de Médecine d Urgence, 1, 15-17.

[13] Ben Salem, F., Ben Salem, K., Grati, L., Arfaoui, C., Faleh, R., et al. (2003) Risk Factors for Eclampsia: A Case-Control Study. Annales Françaises d'Anesthésie et de Réanimation, 22, 865-869. https://doi.org/10.1016/j.annfar.2003.08.006

[14] Beye, M.D., Diouf, E., Kane, O., Ndoye, M.D., Seydi, A., et al. (2003) Management of Severe Eclampsia in Intensive Care in Tropical Africa. About 28 Cases. Annales Françaises d' Anesthésie et de Réanimation, 22, 25-29. https://doi.org/10.1016/S0750-7658(02)00807-9 